\title{
Comment on: Conventional immunosuppression: the search for scientific evidence
}

\author{
Jagdeep Singh Gandhi ${ }^{1}$
}

Received: 30 October 2020 / Revised: 12 November 2020 / Accepted: 25 November 2020 / Published online: 8 December 2020

(c) The Author(s), under exclusive licence to Springer Nature Limited part of Springer Nature 2020

\section{To the Editor:}

With a measure of concurrence I read an editorial from Moorfields Eye Hospital [1]. A point was made about the validity of older immunosuppressives in uveitis treatment. Clearly, we cannot shun these drugs as newer and costlier therapies appear for sale. Older drugs have a 40-year record in ophthalmology and vast knowledge exists due to their use in diverse specialities.

Beside older immunosuppressives the newer biologic drugs are costly. We turn to them with avidness in the same way that we turn to a new car. Yet the older car, when justly assessed, is found to be dependable. Older therapies, such as Mycophenolate or Tacrolimus, may be disfavoured because today's vogue is Adalimumab. In the editorial the musings on commercialism rang true: though effective, old drugs have a shrunken ability to attract money.

Chronic uveitis demands ongoing therapy and drug cost matters in a burgeoning sea of patients. It is de rigueur to say that poorer nations need cheap drugs, but the same holds true for richer ones. Affordable regimens for uveitis can be created using easily obtainable medicines. For example, oral Mycophenolate coupled with periocular steroid. Targeting the systemic immune mechanism, Mycophenolate acts on the backbone of the disease. Under a tolerable theme of tablet ingestion there can still burn a vision-eroding vitritis. Total clarity of the vitreous is, however, attained with an overlay of local steroid. Inflammation is thus tightly controlled, reducing sequelae like epimacular fibrosis.

Jagdeep Singh Gandhi

doctorjsg@gmail.com

1 Worcester Royal Eye Unit, Worcestershire Royal Hospital, Worcester WR5 1DD, United Kingdom
Various local and systemic suppressants of inflammation are found in uveitis care. Biologics were $10 \%$ of the drugs in one report from Germany [2]. Local steroid usage was also conspicuous. Intravitreal steroid is now mainstream, but its uncostly forerunner-periocular steroid-retains a niche. Recently, in the Covid-19 bedlam, after due consent, for uveitis patients I have used subconjunctival Triamcinolone.

On the slit-lamp, a depot is injected at the inferior fornix: in Britain a common option is $20 \mathrm{mg}$ of Triamcinolone (e.g. Kenalog with alcohol vehicle removed). Marked vitreous haze and cells are thereby cleared. Cataract and ocular hypertension may occur, and are dealt with as necessary. Rare adversities can emerge [3]. But such steroid, if bothersome, is readily excisable from the conjunctiva. Also, unlike the posterior subtenon route, the subconjunctival route carries the boon of great repeatability.

Because intravitreal implants are high-priced it is fitting that cheaper care is being sought. Hence work has begun to compare Dexamethasone implant with subconjunctival Triamcinolone [4]. Dexa implant is priced at $£ 1000$ and Kenacort at only £3. If the conjunctival depot has a therapeutic potency that is akin to the implant then the monetary savings will be gargantuan. For uveitis I have found conjunctival steroid to be mightily effectual.

In many clinics a patient can access high-cost drugs, but in many more clinics a patient cannot. While staying upto-date, we should not reject the therapeutic legitimacy of earlier drugs and methods. Evidently, there is scope for the honing of older strategies as the rate of clinic growth outstrips available funds.

\section{Compliance with ethical standards}

Conflict of interest The author declares that he has no conflict of interest.

Publisher's note Springer Nature remains neutral with regard to jurisdictional claims in published maps and institutional affiliations. 


\section{References}

1. Pavesio CE. Conventional immunosuppression: the search for scientific evidence. Eye. 2020;34:1945-6.

2. Ness T, Boehringer D, Heinzelmann S. Intermediate uveitis: pattern of aetiology, complications, treatment and outcome in a tertiary academic centre. Orphanet J Rare Dis. 2017;12:81.
3. Agrawal S, Agrawal J, Agrawal TP. Conjunctival ulceration following triamcinolone injection. Am J Ophthalmol. 2003;136:539-40.

4. Couret C, Poinas A, Volteau C, Riche V-P, Le Lez M-L, Errera M-H, et al. Comparison of two techniques used in routine care for the treatment of inflammatory macular oedema, subconjunctival triamcinolone and intravitreal dexamethasone implant: medical and economic importance of this randomised controlled trial. Trials. 2020;21:159. 